\title{
Desempenho de diferentes substratos na decomposição de carcaça de frango de corte
}

\author{
Taiana Cestonaro' ${ }^{1}$, Paulo G . de Abreu ${ }^{2}$, Valeria M. N . Abreu², Arlei Coldebella ${ }^{2}$, \\ Inaiara L. Tomazelli ${ }^{1} \&$ Marla J. H assemer ${ }^{3}$
}

\begin{abstract}
RESU MO
O bjetivou-se com este trabalho avaliar o desempenho de diferentes substratos na decomposição de carcaça de frango de corte. U tilizaram-se seis câmaras de uma composteira, medindo 0,80 m de largura, $1,20 \mathrm{~m}$ de profundidade e 1,50 m de altura cada uma. 0 s substratos utilizados foram: acícula de pinus, bagaço de cana, palha de milho, casca de amendoim, capim e maravalha. A compostagem foi acompanhada de 4 períodos. A pilha de cada câmara foi montada em 5 camadas, de cujo total foram depositadas, em duas camadas, 5 carcaças de aves, distribuídas uniformemente. A cada 10 dias se realizou o tombamento das pilhas com o objetivo de aerar o substrato e se Ihe adicionou água. A pós 30 dias realizou-se o tombamento final. $\mathrm{Na}$ montagem das pilhas e nos tombamentos pesaram-se, separadamente, as carcaças e os substratos. Durante o processo os parâmetros monitorados foram matéria seca, cinzas, fósforo, potássio, nitrogênio, pH, carbono orgânico e razão $\mathrm{C} / \mathrm{N}$. Todos os substratos foram eficientes na decomposição das carcaças de aves e os valores da composição físico-química final dos substratos estão de acordo com os valores da IN -25/M apa, ou seja, todos os substratos podem ser utilizados como fertilizantes orgânicos simples.
\end{abstract}

Palavras-chave: compostagem, composição físico-química, fertilizantes orgânicos, composto, composteira

\section{Performance of different substrates in the decomposition of broiler carcass}

\begin{abstract}
The aim of this study was to evaluate the performance of different substrates in the decomposition of broiler carcasses. Six containers of a compost maker were used each one measuring $0.80 \mathrm{~m}$ width, 1.20 $\mathrm{m}$ depth and $1.50 \mathrm{~m}$ height. The substrates were: pine aciculae, sugarcane bagasse, corn straw, peanut shells, grass and sawdust. The composting was accompanied by four periods. The pile of each container was made up of five layers, in which, five poultry carcasses were uniformly deposited in two layers. The tumbling of the piles was done every 10 days, with the purpose to provide aeration for the substrate and water was added to the same. After 30 days, the final tumbling was done. In the assembly piles and in the tumbling process the carcasses and the substrate were weighed separately. During the process, the monitored parameters were dry matter, ashes, phosphorus, potassium, nitrogen, pH, organic carbon and $\mathrm{C} / \mathrm{N}$ ratio. All substrates were efficient in the decomposition of the broiler carcasses and final physiochemical composition values are in agreement with values in IN -25/Mapa, in other words, all of the substrates can be used as simple organic fertilizers.
\end{abstract}

Key words: composting, chemical physic composition, organic fertilizers, compost, composter

\footnotetext{
${ }^{1}$ UnC, Rua Victor Sopelsa, 3000 Bairro Salete CEP 89700-000. Concórdia, SC Fone: (49) 3441-1000. E-mail: tcestonaro@hotmail.com; ina_It@yahoo.com.br

2 Embrapa Suínos e Aves, BR 153, KM 110, CEP 89700-000 Concórdia, SC. Fax: (49) 3441.0497. Fone: (49) 3441-0400. E-mail: pabreu@cnpsa.embrapa.br

${ }^{3}$ Ciências Biológicas/Biotecnologia/U N O ESC Joaçaba, SC Rua Getúlio Vargas 2125, Bairro Flor da Serra, CEP 89600-000. Fone: (49) 3551-2000. E-mail: marlajuliane@yahoo.com.br
} 


\section{INTRODUÇÃO}

Atualmente, a cadeia produtiva de frangos de corte no Brasil ocupa, posição de destaque no agribussines brasileiro. Juntamente com o crescimento da produção de aves há aumento da quantidade de resíduos gerados. A mortalidade de frangos de corte no ciclo de produção está em torno de 3 a 5\%, necessitando-se de um destino correto para essas carcaças, do ponto de vista sanitário e ambiental (Abreu et al., 2009).

As formas mais comuns e não recomendadas de disposição das aves mortas são: enterrá-las em locais inapropriados, alimentação de outras espécies animais, incineração inadequada e até mesmo seu lançamento em córregos e matas (Costa et al., 2005). Essas práticas, usualmente realizadas, apresentam inconvenientes, pois geram passivos ambientais e problemas de saúde pública. A má destinação desses resíduos provoca a depreciação da paisagem, odores oriundos da degradação da matéria orgânica, proliferação de vetores como moscas, formigas, baratas, ratos e mosquitos, contaminação das águas superficiais e dos lençóis freáticos, e presença de chorume, líquido altamente poluente, originado da decomposição dos resíduos orgânicos (Salvaro et al., 2007). A disposição ecologicamente adequada das aves mortas em sistemas avícolas requer estudos sobre alternativas que contemplem o aspecto econômico, técnico, social e ambiental. A compostagem, processo biológico de reciclagem de nutrientes, se enquadra nessa prática (Costa et al., 2005; Dias \& Vaz, 1996).

A compostagem, como processo de bioxidação aeróbia exotérmica de um substrato orgânico heterogêneo no estado sólido, se caracteriza pela produção de $\mathrm{CO}_{2}$, água, liberação de substâncias minerais e formação de matéria orgânica estável (Bruni, 2005). O processo de compostagem possui a vantagem de, quando devidamente conduzido, ser uma prática relativamente barata e ambientalmente correta para a disposição das carcaças de aves (Costa et al., 2005; 2006).

Sendo, então, a compostagem um processo aeróbio, o fornecimento de ar é vital à atividade microbiana, pois os microorganismos aeróbios têm necessidade de $\mathrm{O}_{2}$ para oxidar a matéria orgânica que lhes serve de alimento. A falta deste elemento pode tornar-se fator limitante para a atividade microbiana e prolongar o ciclo de compostagem (Fernandes \& Silva, 1999).

Segundo Barreira et al. (2006) na compostagem existem muitos fatores que interferem ou influenciam a decomposição, a maturação e a qualidade do produto final podendo-se citar a umidade, a temperatura, a relação $\mathrm{C} / \mathrm{N}$ e os resíduos orgânicos utilizados.

A temperatura é importante, principalmente no que diz respeito à rapidez do processo de biodegração e à eliminação de patógenos (Fernandes \& Silva, 1999). A umidade é também considerada parâmetro significativo para controle do processo de compostagem, cujo valor pode variar em torno de $55 \%$. Teores de umidade muito baixos reduzem a atividade microbiana. No contexto contrário, altos teores de umidade dificultam a difusão do oxigênio, tornando o meio anaeróbio, com produção de gases e o desenvolvimento de maus odores (Bruni, 2005).

$\mathrm{O}$ pH da massa de compostagem não é, usualmente, um fator crítico no processo. Nos primeiros dias da compostagem a acidez do material tende a aumentar em virtude da formação de ácidos orgânicos. Após este período inicial o pH tende a ficar na faixa alcalina, situando-se, na fase final, em torno de 7,5 e 9 (Bruni, 2005).

Teoricamente, a relação $\mathrm{C} / \mathrm{N}$ inicial ótima do substrato deve situar-se em torno de 30:1; na realidade, ela pode variar de 20:1 a 70:1 de acordo com a maior ou menor biodegradabilidade do substrato. No final da compostagem a relação $\mathrm{C} / \mathrm{N}$ converge para valores de 10:1 e 20:1 (Fernandes \& Silva, 1999).

O composto final, húmus, é um complexo de vários elementos juntos (Diniz Filho et al., 2007). Ele age no suprimento dos nutrientes para as plantas, na estrutura e na compatibilidade do solo e na capacidade de retenção de água (Budziak et al., 2004).

A utilização de substratos inadequados na compostagem impede a fermentação dos resíduos, levando à putrefação e, como consequência, escolher o material adequado como substrato para a realização do composto é um avanço significativo na busca da melhoria do processo e da degradação eficiente das carcaças. Assim, procurou-se avaliar o desempenho de diferentes substratos na decomposição de carcaça de frango de corte.

\section{Material e MÉTOdos}

O experimento foi realizado na Embrapa Suínos e Aves, Campo experimental de Suruvi, Concórdia, SC. O período experimental foi de agosto de 2008 a fevereiro de 2009. A composteira foi formada de seis câmaras, medindo $0,80 \mathrm{~m}$ de largura, 1,20 m de profundidade e 1,50 $\mathrm{m}$ de altura, cada uma. As câmaras foram construídas com piso de concreto e paredes de madeira, com cobertura de telhas de cimento amianto. Em cada câmara foi empregado um substrato diferente. Os substratos avaliados foram: acícula de pinus, bagaço de cana, palha de milho, casca de amendoim, capim e maravalha. Esses substratos foram escolhidos por serem de fácil obtenção na região Oeste Catarinense e de baixo custo. Realizaram-se quatro repetições no tempo. As aves utilizadas na compostagem foram abatidas, permanecendo no aviário sobre a cama por $24 \mathrm{~h}$, simulando situação encontrada a campo. Em cada câmara foram colocadas 10 aves divididas em duas camadas por pilha de substrato. Utilizaram-se 60 aves por lote e 240 no final dos quatro lotes. Antes da montagem das pilhas as aves e os substratos foram pesados separadamente. As aves foram pesadas para o cálculo da quantidade de água a ser agregada para o umedecimento das camadas. Esta quantidade de água equivale a $30 \%$ do peso das aves (Abreu et al., 2009).

A pilha de cada câmara foi montada em 5 camadas, as quais, com espessura de 40,10,15, 10 e $30 \mathrm{~cm}$, correspondem a 1, 2, 3, 4 e 5 , respectivamente. A primeira camada foi montada com substrato, a segunda com 5 carcaças + substrato, a terceira camada com substrato, a quarta com 5 carcaças + substrato e a quinta e última camada com substrato. Todas as pilhas foram formadas desta mesma maneira. A cada 10 dias se realizou o tombamento das pilhas, no total de três tombamentos, com o objetivo de aerar o substrato e adicionar água ao mesmo, remontando a pilha com a mesma ordem das camadas e dos 
substratos. Na montagem das pilhas e a cada tombamento realizou-se a pesagem das carcaças e dos substratos, em separado e por camada. Para a pesagem dos substratos e das carcaças de aves foi utilizada uma balança eletrônica marca Toledo®, modelo 2124-C5, com capacidade para 100 kg. Após 30 dias realizou-se o tombamento final. Em cada tombamento foram coletadas amostras dos substratos por camada em cada câmara, para análises laboratoriais. Coletaram-se, em cada camada, 9 subamostras em diferentes pontos, com o auxílio de um gabarito as quais foram, posteriormente, homogeneizadas. Como se montaram 5 camadas em cada pilha, no final dos 4 lotes se obtiveram 20 amostras de cada substrato.

As análises físico-químicas dos substratos foram realizadas no Laboratório de Análises Físico-Químicas da Embrapa Suínos e Aves e analisados os níveis de matéria seca, cinzas, fósforo, potássio, nitrogênio total, $\mathrm{pH}$ e calculada a relação $\mathrm{C} / \mathrm{N}$. Visando à determinação do carbono orgânico, utilizou-se a Eq. 1 .

$$
\mathrm{MO}=1,724 \times \mathrm{C}
$$

em que:

$$
\begin{aligned}
& \text { MO - matéria orgânica, em \% } \\
& \text { C - carbono orgânico, em \% }
\end{aligned}
$$

Os dados de compostagem de carcaça de aves dos seis tipos de substrato, foram analisados por meio de análise de modelos mistos para medidas repetidas, considerando-se os efeitos lote, substrato (parcela), camada (subparcela), tempo de compostagem (sub-subparcela) e as interações das três últimas variáveis, além de 3 tipos de estrutura de matriz de variâncias e covariâncias, usando-se o programa Proc Mixed do SAS, conforme Xavier (2000), sendo que a estrutura a ser utilizada na análise foi escolhida com base no menor valor do critério de informação de akaike (AIC). O método de estimação empregado foi o de máxima verossimilhança restrita. Para o detalhamento da análise dos substratos foi utilizado o teste de Tukey-Kramer.

\section{RESULTADOS E DISCUSSÃO}

Apresentam-se, na Tabela 1, os níveis descritivos de probabilidade do teste $\mathrm{F}$ para a \% de decomposição das carcaças. A matriz de variâncias e covariâncias usada na análise foi a do tipo produto direto entre uma matriz sem estrutura e uma autorregressiva de primeira ordem. Observa-se que houve efeito significativo $(\mathrm{p}<0,05)$ apenas de lote, tempo de compostagem e da interação entre tempo de compostagem e substrato.

Apesar de haver efeito significativo da interação entre tempo de compostagem e substrato, não ocorreu diferenças significativas $(\mathrm{p}>0,05)$ entre os substratos dentro de cada tempo de compostagem. Verificam-se, na Figura 1, os perfis médios da percentagem de decomposição de carcaça em função do substrato e do tempo de compostagem. A análise de regressão para tempo de compostagem dentro de cada substrato demonstrou haver efeito quadrático para o substrato acícula de pinus e linear para os demais substratos.
Tabela 1. Níveis descritivos de probabilidade do teste $F$ da análise da variância para \% de decomposição das carcaças

\begin{tabular}{lcc}
\hline \multicolumn{1}{c}{ Causas de variação } & $\begin{array}{c}\text { Graus de } \\
\text { liberdade }\end{array}$ & Pr > F \\
Lote & 3 & 0,0079 \\
Substrato & 5 & 0,8925 \\
Camada & 1 & 0,6515 \\
Substrato $\times$ camada & 5 & 0,7831 \\
Tempo de compostagem & 2 & $<0,0001$ \\
Substrato $\times$ tempo de compostagem & 10 & 0,0192 \\
Camada $\times$ tempo de compostagem & 2 & 0,3282 \\
Substrato $\times$ camada $\times$ tempo de compostagem & 10 & 0,7453 \\
\hline
\end{tabular}

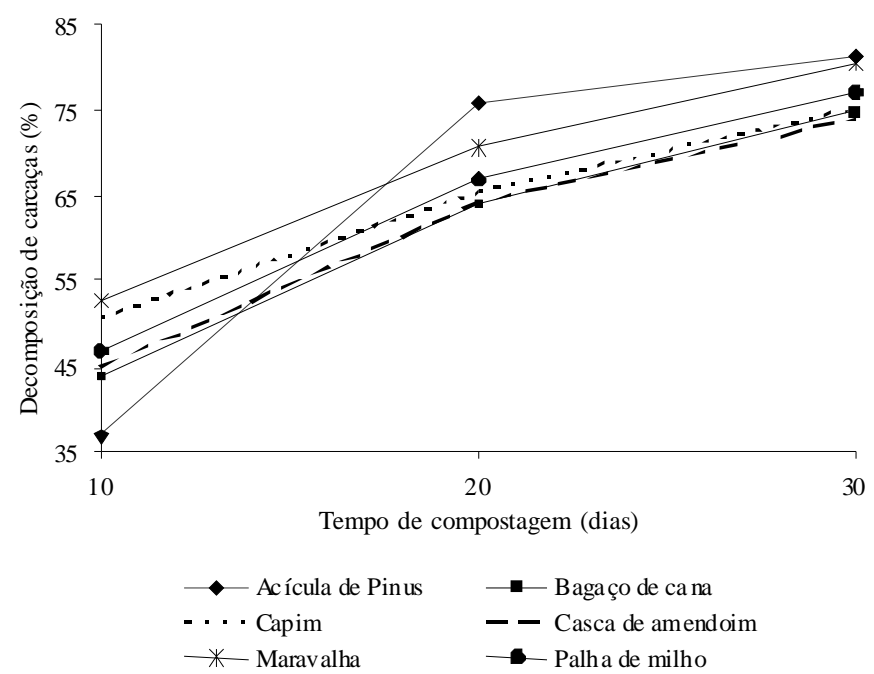

Figura 1. Perfis médios da \% de decomposição de carcaça em função do substrato e do tempo de compostagem

Na Tabela 2 se encontram os valores médios e erros padrão da composição inicial dos substratos da compostagem. Houve diferença significativa para todos os parâmetros avaliados em relação aos substratos, exceto para a umidade. O maior e o menor valor de carbono orgânico foram observados para os substratos maravalha e capim, respectivamente. Os maiores valores de nitrogênio foram encontrados nos substratos capim e casca de amendoim, enquanto o menor valor foi no substrato maravalha. Para o fósforo, o maior valor de concentração foi no substrato capim; já os demais substratos não diferem em relação ao menor valor de concentração. O potássio também indicou maiores concentrações para o substrato capim e menores concentrações para os outros substratos. Em relação ao $\mathrm{pH}$, os substratos que apresentaram maiores valores foram a palha de milho e o capim, e o que mostrou menor valor foi a maravalha. A maior relação de $\mathrm{C} / \mathrm{N}$ foi observada no substrato maravalha. Devido à grande variabilidade de substratos utilizados neste experimento, observou-se que alguns substratos estavam dentro da faixa inicial ótima de relação $\mathrm{C} / \mathrm{N}$ (20-70) sendo esses substratos o capim, a casca de amendoim e a acícula de pinus (Fernandes \& Silva, 1999), porém os outros substratos se encontram acima desses valores. Para o parâmetro cinzas, o maior e o menor percentual foram observados nos substratos capim e maravalha, respectivamente. 
Tabela 2. M édias e erros padrão da composição inicial dos substratos da compostagem

\begin{tabular}{lcccccc}
\hline \multicolumn{1}{c}{ Parâmetro } & Acícula de pinus & Bagaço de cana & Palha de milho & Casca de amendoim & Capim & Maravalha \\
C Org (\%) & $56 \pm 0,1 \mathrm{ab}$ & $56,2 \pm 0,1 \mathrm{ab}$ & $56 \pm 0,1 \mathrm{ab}$ & $55 \pm 0,4 \mathrm{~b}$ & $50,5 \pm 1 \mathrm{c}$ & $57,8 \pm 0 \mathrm{a}$ \\
Umidade (\%) & $17,51 \pm 2,06$ & $16,47 \pm 0,45$ & $16,44 \pm 1,31$ & $15,76 \pm 0,92$ & $18,26 \pm 1,66$ & $14,55 \pm 2,23$ \\
Nitrogênio (\%) & $0,942 \pm 0,229 \mathrm{~b}$ & $0,561 \pm 0,185 \mathrm{bc}$ & $0,57 \pm 0,109 \mathrm{bc}$ & $1,849 \pm 0,177 \mathrm{a}$ & $2,23 \pm 0,098 \mathrm{a}$ & $0,263 \pm 0,059 \mathrm{c}$ \\
Fósforo (\%) & $0,083 \pm 0,015 \mathrm{~b}$ & $0,123 \pm 0,012 \mathrm{~b}$ & $0,11 \pm 0,013 \mathrm{~b}$ & $0,139 \pm 0,018 \mathrm{~b}$ & $0,314 \pm 0,036 \mathrm{a}$ & $0,058 \pm 0,005 \mathrm{~b}$ \\
Potássio (\%) & $0,121 \pm 0,032 \mathrm{~b}$ & $0,506 \pm 0,057 \mathrm{~b}$ & $0,714 \pm 0,045 \mathrm{~b}$ & $0,398 \pm 0,08 \mathrm{~b}$ & $1,676 \pm 0,249 \mathrm{a}$ & $0,094 \pm 0,016 \mathrm{~b}$ \\
$\mathrm{pH}$ & $5,53 \pm 0,27 \mathrm{bc}$ & $5,92 \pm 0,36 \mathrm{abc}$ & $7,11 \pm 0,06 \mathrm{a}$ & $6,85 \pm 0,10 \mathrm{ab}$ & $6,91 \pm 0,28 \mathrm{a}$ & $5,13 \pm 0,39 \mathrm{c}$ \\
$\mathrm{C} / \mathrm{N}$ & $68,51 \pm 11,1 \mathrm{~b}$ & $139 \pm 35 \mathrm{ab}$ & $111 \pm 20 \mathrm{~b}$ & $31,73 \pm 3,52 \mathrm{~b}$ & $22,97 \pm 1,07 \mathrm{~b}$ & $253 \pm 36 \mathrm{a}$ \\
Cinzas (\%) & $3,41 \pm 0,17 \mathrm{bc}$ & $3,14 \pm 0,25 \mathrm{bc}$ & $3,51 \pm 0,14 \mathrm{bc}$ & $5,16 \pm 0,63 \mathrm{~b}$ & $12,87 \pm 1,67 \mathrm{a}$ & $0,44 \pm 0,06 \mathrm{c}$ \\
\hline
\end{tabular}

Médias seguidas de letras distintas nas linhas diferem pelo teste Tukey-Kramer $(p<0,05)$

Na Tabela 3 se tem os valores médios e erros padrões da composição final dos substratos da compostagem, após 4 períodos. Para a composição final dos substratos constatouse diferença significativa em todos os parâmetros avaliados, exceto para a umidade, mantendo o mesmo comportamento inicial. Costa et al. (2009) utilizando a palha de trigo na compostagem de resíduos sólidos frigoríficos observaram que este substrato conferiu maior uniformidade de aeração porém vem ser um ponto negativo no sentido de retenção de água pois os mesmos espaços vazios que permitem a circulação de ar na leira também permitem o escorrimento da água desprendida no processo, ocasionando o chorume. $\mathrm{O}$ menor valor de carbono orgânico foi observado no substrato capim e os maiores valores nos demais substratos, não havendo diferença significativa. As concentrações de nitrogênio atingiram os maiores valores nos substratos capim e casca de amendoim $(2,65$ e $2,31 \%)$ e o menor valor no substrato maravalha $(0,59 \%)$. Primo et al. (2010) encontraram, na compostagem com resíduos de fumo, valores de nitrogênio no composto final (após 120 dias) entre 1,64 e 1,85\%. Os níveis de fósforo foram maiores para o substrato capim e menores para o substrato maravalha; da mesma forma, os níveis de potássio também foram maiores para o substrato capim e menores para o substrato maravalha. Observaram-se os maiores valores de $\mathrm{pH}$ para quatro substratos (capim, palha de milho, casca de amendoim e maravalha), e o menor valor para o substrato bagaço de cana. Para a razão $\mathrm{C} / \mathrm{N}$ o substrato que apresentou maior valor foi a maravalha e os menores valores foram constatados para a casca de amendoim e capim. Segundo Fernandes \& Silva (1999) a razão C/N final da compostagem converge para valores entre 10 e 20 . Analisando a Tabela 3, percebe-se que somente o substrato capim possui valor de $\mathrm{C} / \mathrm{N}$ nesta faixa, fato explicado visto que os substratos já iniciaram o processo de compostagem com uma relação $\mathrm{C} / \mathrm{N}$ acima da recomendada e cada substrato possui característica própria, necessitando de um tempo de compostagem diferente para atingir os valores citados na literatura. Costa et al. (2009) constataram valores da relação C/ $\mathrm{N}$ de 10,7:1, após 90 dias de compostagem de resíduos sólidos de frigorífico. Os maiores valores de cinzas foram observados para o capim e os demais substratos não se diferenciaram quanto aos menores valores de cinzas.

Analisando a composição inicial e a composição final dos substratos, percebe-se que todos apresentaram redução do carbono orgânico e da relação C/N. Segundo Maragno et al. (2007) durante a compostagem a degradação da matéria orgânica leva a uma redução do carbono orgânico, explicando a diminuição do carbono orgânico e também da relação $\mathrm{C} / \mathrm{N}$. Lima et al. (2009) também observaram decréscimo no carbono orgânico dos resíduos da produção de biodiesel compostados com adição mineral, enquanto o nitrogênio total aumentou. Para os parâmetros umidade, nitrogênio, fósforo, $\mathrm{pH}$ e cinzas, notou-se um aumento para todos os substratos em relação à composição inicial. Os substratos foram utilizados "in natura" enquanto na maioria dos sistemas de compostagem é utilizada a cama de aves como substrato que, além de carbono, possui matéria orgânica e umidade. Segundo Abreu et al. (2009) a quantidade de água a ser agregada na compostagem de carcaça de aves equivale a $30 \%$ do peso das aves. Desta forma, a utilização de $30 \%$ de água em relação ao peso da ave é eficiente para a decomposição das aves, porém não o é para a decomposição total do substrato. Quando a umidade do substrato é insuficiente resulta em mumificação das carcaças. Para Matos et al. (1998) houve acúmulo de nitrogênio durante o processo de compostagem em virtude da concentração do material em decorrência da liberação de gases e do vapor dágua, com a decomposição do material orgânico por microorganismos, corroborando com os dados apresentados nas Tabelas 2 e 3. Apenas os substratos bagaço de cana e acícula de pinus não atingiram valores finais de $\mathrm{pH}$ básicos, mostrando que poderia ser necessário um período maior de compostagem para se atingir o pH básico, conforme Bruni (2005). Os acréscimos nos teores dos nutrientes são devidos à

Tabela 3. M édias e erros padrão da composição final dos substratos da compostagem após 4 lotes

\begin{tabular}{|c|c|c|c|c|c|c|c|}
\hline Parâmetro & Acícula de pinus & Bagaço de cana & Palha de milho & Casca de amendoim & Capim & Maravalha & IN-25 \\
\hline C Org (\%) & $55,8 \pm 0,1 a$ & $55,8 \pm 0,1 a$ & $55,6 \pm 0,1 a$ & $54 \pm 0,2 \mathrm{a}$ & $49,6 \pm 1,5 b$ & $57,6 \pm 0 a$ & $\geq 15$ \\
\hline Umidade (\%) & $20,56 \pm 1,37$ & $20,18 \pm 2,80$ & $20,03 \pm 1,69$ & $18,03 \pm 1,29$ & $21,35 \pm 2,20$ & $21,3 \pm 2,85$ & $\leq 40$ \\
\hline Nitrogênio (\%) & $1,65 \pm 0,145 b$ & $1,28 \pm 0,134 b c$ & $1,05 \pm 0,097 \mathrm{~cd}$ & $2,31 \pm 0,057 a$ & $2,65 \pm 0,122 \mathrm{a}$ & $0,59 \pm 0,034 d$ & $\geq 0,5$ \\
\hline Fósforo (\%) & $0,142 \pm 0,003 b c$ & $0,151 \pm 0,023 b c$ & $0,162 \pm 0,017 b c$ & $0,201 \pm 0,007 b$ & $0,346 \pm 0,022 a$ & $0,097 \pm 0,021 c$ & - \\
\hline Potássio (\%) & $0,212 \pm 0,035 a b$ & $0,47 \pm 0,114 a b$ & $0,607 \pm 0,16 a b$ & $0,365 \pm 0,075 a b$ & $1,173 \pm 0,392 \mathrm{a}$ & $0,123 \pm 0,016 b$ & - \\
\hline $\mathrm{pH}$ & $6,89 \pm 0,09 a b$ & $6,27 \pm 0,24 b$ & $7,68 \pm 0,18 a$ & $7,72 \pm 0,20 a$ & $7,88 \pm 0,18 a$ & $7,49 \pm 0,24 a$ & c.d* \\
\hline $\mathrm{C} / \mathrm{N}$ & $36,34 \pm 3,15 b c$ & $49,27 \pm 6,71 b$ & $63,67 \pm 5,21 b$ & $23,97 \pm 0,39 c$ & $18,95 \pm 0,78 c$ & $115 \pm 8 a$ & - \\
\hline Cinzas (\%) & $3,75 \pm 0,12 b$ & $3,77 \pm 0,21 b$ & $4,07 \pm 0,16 b$ & $6,95 \pm 0,43 b$ & $14,51 \pm 2,60 a$ & $0,74 \pm 0,08 b$ & - \\
\hline
\end{tabular}

*c.d - conforme declarado

Médias seguidas de letras distintas nas linhas diferem pelo teste Tukey-Kramer $(p \leq 0,05)$ 
disponibilização ocorrida pela ação microbiana no material (Costa et al., 2005); entretanto, o potássio foi o único parâmetro que não apresentou este comportamento entre os substratos. Como a variação de concentração do potássio foi pequena em relação ao tempo de compostagem, referido comportamento de aumento de concentração para alguns substratos e diminuição da concentração para outros, pode ter sido em decorrência da amostragem.

Todos os valores obtidos ao final da compostagem estão de acordo com os valores contemplados na IN-25/Mapa, ou seja, todos os substratos podem ser utilizados como fertilizantes orgânicos simples, segundo as normas do Ministério da Agricultura, Pecuária e Abastecimento.

\section{ConClusões}

1. Todos os substratos foram eficientes na decomposição das carcaças de aves.

2. Os valores da composição físico-química final dos substratos estão de acordo com os valores contemplados na IN-25/Mapa, ou seja, todos os substratos podem ser utilizados como fertilizantes orgânicos simples.

3. Esses substratos também podem ser reutilizados mais vezes, mantendo os $30 \%$ de água.

\section{LITERATURA CITADA}

Abreu, V. M. N.; Pedroso-de-Paiva, D.; Abreu, P. G.; Coldebella, A. Desempenho da casca de arroz e da palhada de soja na decomposição de carcaças de frangos de corte. In: Simpósio Internacional sobre Gerenciamento de Resíduos de Animais, 1, 2009. Anais... Florianópolis: SIGERA, 2009. CD Rom

Barreira, L. P.; Philippi Júnior, A.; Rodrigues, M. S. Usinas de compostagem do Estado de São Paulo: qualidade dos compostos e processos de produção. Engenharia Sanitária e Ambiental, v.11, n.4, p.385-393, 2006.

Bruni, V. Avaliação do processo operacional de compostagem aerada de lodo de esgoto e poda vegetal em reatores fechados. Curitiba: UFPR. 2005. 95p. Dissertação Mestrado

Budziak, C. R.; Maia, C. M. B. F.; Mangrich, A. S. Transformações químicas da matéria orgânica durante a compostagem de resíduos da indústria madeireira. Química Nova, v.27, n.3, p.399-403, 2004.

Costa, M. S. S. de M.; Costa, L. A. de M.; Decarli, L. D.; Pelá, A.; Silva, C. J. da.; Matter, U. F.; Olibone, D. Compostagem de resíduos sólidos de frigorífico. Revista Brasileira de Engenharia Agrícola e Ambiental, v.13, p.100-107, 2009.
Costa, M. S. S. de M.; Costa, L. A. de M.; Olibone, D.; Röder, C.; Burin, A.; Kaufmann, A. V.; Ortolan, M. L. Efeito da aeração no primeiro estágio da compostagem de carcaça de aves. Revista Engenharia Agrícola, v.25, n.2, p.549-556, 2005.

Costa, M. S. S. de M.; Costa, L. A. de M.; Pelá, A.; Silva, C. J. da.; Decarli, L. D.; Matter, U. F. Desempenho de quatro sistemas para compostagem de carcaça de aves. Revista Brasileira de Engenharia Agrícola e Ambiental, v.10, p.692698, 2006.

Dias, S. M. F.; Vaz, L. M. S. Método de monitoramento no processo aeróbico de compostagem - EEA/UEFS. Revista Sitientibus, v.15. p.233-240, 1996.

Diniz Filho, E. T.; Mesquita, L. X. de.; Oliveira, A. M. de.; Nunes, C. G. F.; Lira, J. F. B. de. A prática da compostagem no manejo sustentável de solos. Revista Verde de Agroecologia e Desenvolvimento Sustentável, v.2, n.2, p.27-36, 2007.

Fernandes, F.; Silva, S. M. C. P. da. Manual prático para a compostagem de biossólidos. Rio de Janeiro: Associação Brasileira de Engenharia Sanitária e Ambiental, 1999. 84p.

Lima, C. C.; Mendonça, E. S.; Silva, I. R.; Silva,L. H. M.; Roig A. Caracterização química de resíduos da produção de biodiesel compostados com adição mineral. Revista Brasileira de Engenharia Agrícola e Ambiental, v.13, n.3, p.334-340, 2009.

MAPA - Ministério da Agricultura, Pecuária e Abastecimento. Instrução Normativa n. 23, de 31 de agosto de 2005.

Maragno, E. S.; Trombin, D. F.; Viana, E. O uso da serragem no processo de minicompostagem. Engenharia Sanitária e Ambiental, v.12, p.355-360, 2007.

Matos, A. T. de.; Vidigal, S. M.; Sediyama, M. A. N.; Garcia, N. C. P.; Ribeiro, M. F. Compostagem de alguns resíduos orgânicos utilizando-se águas residuárias da suinocultura como fonte de nitrogênio. Revista Brasileira de Engenharia Agrícola e Ambiental, v.2, n.2, p.199-203, 1998.

Primo, D. C.; Fadigas, F. de S.; Carvalho, J. C. R.; Schmidt, C. D. S.; Borges Filho, A. C. S. Avaliação da qualidade nutricional de composto orgânico produzido com resíduos de fumo. Revista Brasileira de Engenharia Agrícola e Ambiental, v.14, p.742-746, 2010.

Salvaro, E.; Baldin, S.; Costa, M. M.; Lorenzi, E. S.; Viana, E.; Pereira, E. B. Avaliação de cinco tipos de minicomposteiras para domicílios do bairro pinheirinho da cidade de Criciúma/ SC. Revista Com Scientia, v.3, n.3, p.12-21, 2007.

Xavier, L. H. Modelos univariado e multivariado para análise de medidas repetidas e verificação da acurácia do modelo univariado por meio de simulação. Piracicaba: USP, 2000. 91p. Dissertação Mestrado 